\title{
Optimization of industrial production of feed blends by fuzzy multi-criteria
} programming methods

\author{
Tunjo Peric ${ }^{1,2}$, Zoran Babic ${ }^{3}$ \\ (1. Bakeries Sunce, Bestovje 10437, Croatia; \\ 2. Faculty of Economics, University of Tuzla, Tuzla 75000, Bosnia and Herzegovina; \\ 3. Faculty of Economics, University of Split, Split 21000, Croatia)
}

\begin{abstract}
This paper presents a model for optimizing industrial production of blend for livestock feed by application of a fuzzy multi-criteria programming method. This paper (1) considers multicriteria problem of industrial production of feed blend optimization in vague conditions, (2) proposes a fuzzy multiple criteria programming (FMCP) model for industrial production of feed blend optimization in vague conditions, (3) applies the proposed model in solving the concrete problem of industrial production of feed blend optimization and (4) points to the advantages of the model usage through sensitivity analysis of compromise solutions.
\end{abstract}

Key words: livestock feed; costs; blend quality; fuzzy multi-criteria programming

\section{Introduction}

Industrial production of feed blends involves mixing of single ingredients that are simultaneously used for feeding of various kinds and categories of domestic animals. The optimal mix of ingredients in industrial production of livestock feed has to be satisfactory in terms of quality and cost considering the need for particular sorts of feed and their seasonal availability.

While the feed has to meet the nutritional requirements of livestock to allow maximal weight gain, its industrial production has to be economical, which can only be ensured by an optimal blending of ingredients.

Optimization of industrial production of feed blends in terms of their nutritive value and in terms of economic criteria can be carried out by application of mathematical optimization methods. The benefit of application of these methods is the fast and efficient solution for the optimal combination of ingredients considering the nutritive needs of animals and constraints in their availability. Unlike the standard feed problem where the requirements for basic nutrients have to be met at minimised costs and which is solved mainly by linear programming, the authors also introduce the goals of meal quality where different requirements of decision makers are modelled by fuzzy multicriteria programming.

The idea on the application multiple-criteria decision making (MCDM) in feed blend optimization stems from Rehman and Romero (1984), who applied MCDM techniques which include goal programming and its variants, such as weighted and lexicographic approaches, and multiple-objective programming to determine the optimal feed blend for dairy cows. Their optimization criteria were: (1) blend cost minimization, (2) minimization

Tunjo Perić, Ph.D., general manager at Bakeries Sunce, assistant professor at Faculty of Economics, University of Tuzla; research fields: operational research, quantitative methods in managemet, econometrics methods in management.

Zoran Babić, Ph.D., professor, Faculty of Economics, University of Split; research fields: operational research, quantitative methods for decision making, multicriterial decision making. 
of share of any ingredient in the blend, and (3) minimization of dry matter in the blend. Lara and Romero (1992, 1994) consider nutrition requirements as goals that are either feasible or not feasible. Thus, they formulate the multiple-criteria programming model that is solved by application of interactive STEM method. In addition to the minimal cost criterion, Lara (1993) introduces maximization of blend ingredients available on the farm. For that purpose, multicriteria non-linear programming model is built. Tozer and Stokes (2001) investigate the potential of multiple objective programming to reduce nutrient excretion from dairy cows by incorporating nutrient excretion functions into a ration formulation framework. Bailleul, Rivest, Dubeau and Pomar (2001) develop a multiple goal programming method for simultaneous minimization of cost and excess nitrogen in pig diets. Zhang and Roush (2002) consider feed blend optimization in terms of several goals. Castrodeza, Lara and Pena (2005) use interactive multiple goal programming to determine an optimal meal for porkers. To evaluate optimality of the blend, they use four criteria types: economic, nutritional, nutritional-ecological and ecological.

The aims of this work are: (1) to point on the concrete example that optimization of feed blend production is essentially a multi-criteria problem, (2) to develop a fuzzy multi-criteria programming model which allows optimization of feed blend production for different kinds and categories of livestock, (3) to apply a fuzzy multi-criteria programming method in solving the problem of the concrete pig farming company (4) to analyze the obtained solutions and point to the strengths of the formed model as well as to the possibilities of further research in this field.

The rest of the paper is organized as follows: Methodology for problem solving by application of the fuzzy multicriteria programming approach is proposed in section 2. In section 3, this methodology is applied in a company dealing with pig farming and preparation of feed blend. Besides, the analysis of the obtained solutions is conducted in this section. Concluding remarks are stated in section 4.

\section{Methodology for solving the problem of industrial feed blend production}

To optimize industrial feed blend production, the authors propose the following methodology:

(1) Determination of sorts and quantities of the required feed blends;

(2) Determination of criteria and optimization constraints;

(3) Building and solving the FLP model;

(4) Analysis of the obtained solutions.

\subsection{Determination of sorts and quantities of feed blends}

In optimization of industrial production of feed blends for a particular period, it is first necessary to define the sorts and quantities of the required feed blends, which naturally has to be adjusted to the feed blend production plan for a particular period.

\subsection{Criteria and constraints in optimization of industrial production of feed blends}

Criteria used for optimization of the feed blend for particular types and categories of animals can vary from one author to another. Which criteria will be used depends mostly on the goals of the decision maker.

When determining criteria for optimization of feed blend production, the factors to be considered are:

- The cost of blend preparation;

- The nutrition needs of animals for which the blends are prepared;

- The blend quality.

It would be ideal if the costs were minimal, the nutrition needs completely satisfied and the blend quality 
maximal. Consequently, the criteria for optimization of feed blend production are:

(1) Cost expressed in monetary units;

(2) The share of ingredients necessary to satisfy the needs for maximal weight gain;

(3) The share of ingredients that negatively affect the blend quality and thus also the weight gain.

The constraints emerging in the optimization of feed blend production are: (1) minimal and maximal requirements of animals for nutritional elements in the blend, (2) market constraints in terms of availability of feed blend ingredients and (3) market constraints in terms of demand for the feed blend quantities.

\subsection{Building and solving the FMCP model}

Consequently, the problem of determining the optimal feed blend production for particular kinds and categories of livestock is the multi-criteria programming problem. If we want to solve the problem by fuzzy MCP methods, we have to start from the following:

- Sorts and quantities of the required feed blends are defined.

- Criteria for determination of the optimal feed blend are given.

- The feed blends have to meet the needs for nutrients of the given animal kinds and categories.

- Particular feed sorts and quantities are available that can be used as blend components.

Let us introduce the following marks:

$f_{j}$ : criteria functions $(j=1, \ldots, k)$;

$b_{l q}:$ need for a nutrient of $l$ kind in the blend unit $q(l=1, \ldots, m ; q=1, \ldots, z)$;

$n$ : number of available ingredients;

$c_{i j q}: i$ coefficient of $j$ criterion function for $q$ blend $(i=1, \ldots, n ; j=1, \ldots, k ; q=1, \ldots, z)$;

$x_{i q}$ : quantity of $i$ ingredient in $q$ blend $(i=1, \ldots, n ; q=1, \ldots, z)$;

$a_{i l}$ : quantity of $l$ nutrient per unit of $i$ ingredient $(i=1, \ldots, n ; l=1, \ldots, m)$;

$d_{i}$ : available quantity of $i$ ingredient $(i=1, \ldots, n)$;

$a_{q}$ : the needed quantity of $q$ blend $(q=1, \ldots, z)$;

$u_{i q}$ : maximal share of $i$-ingredient in $q$ blend $(q=1, \ldots, z)$;

$t_{i q}$ : minimal share of $i$-ingredient in $q$ blend $(q=1, \ldots, z)$.

Now we can form a FMCP model for optimization of feed blend production:

$$
\begin{gathered}
(\min ) \underline{f}_{r}=\left[f_{1}, f_{2}, \ldots, f_{p}\right]=\left[\sum_{i=1}^{n} \sum_{q=1}^{z} c_{i 1 q} x_{i q}, \ldots, \sum_{i=1}^{n} \sum_{q=1}^{z} c_{i p q} x_{i q}\right] \\
(\max ) \underline{f}_{s}=\left[f_{p+1}, f_{p+2}, \ldots, f_{k}\right]=\left[\sum_{i=1}^{n} \sum_{q=1}^{z} c_{i, p+1, q} x_{i q}, \ldots, \sum_{i=1}^{n} \sum_{q=1}^{z} c_{i k q} x_{i q}\right]
\end{gathered}
$$

subject to:

$$
\begin{gathered}
\sum_{i=1}^{n} a_{i l} x_{i q} \geq a_{q} b_{l q} \quad(l=1, \ldots, m ; q=1, \ldots, z) \\
\sum_{i=1}^{n} x_{i q}=a_{q} \quad(q=1, \ldots, z) \\
\sum_{q=1}^{z} x_{i q} \leq d_{i} \quad(i=1, \ldots, n) \\
t_{i q} \leq x_{i q} \leq u_{i q} \quad(i=1, \ldots, n ; q=1, \ldots, z) \\
x_{i q} \geq 0 \quad(i=1, \ldots, n ; q=1, \ldots, z)
\end{gathered}
$$

Application of the model (equation (1)-equation (7)) assumes the ability of the decision maker to select the 
preferred solution, which means that the decision maker is familiar with the model and able to recognize the solution that gives preferred values to criteria functions. However, in most real cases the decision maker is not able to determine precisely the contribution of criteria functions to the general goal of business operation, and he can hardly be expected to recognize the trade-off between particular criteria functions. Therefore, it is necessary to develop a fuzzy multicriteria model and to solve it as the fuzzy multicriteria programming model.

Fuzzy decision making can be symmetrical and asymmetrical. In symmetrical fuzzy decisions differences between importance of criteria functions and constraints are not introduced, while in asymmetrical multicriteria decisions criteria functions and constraints do not have equal value and have different weights (Zimmermann; 1978; Zimmermann; 1987; Sakawa,1993).

The general model of multicriteria feed blend optimization (equation (1)-equation (7)) may be presented as:

Find the vector $\underline{x}$ which minimizes the criteria functions $f_{r}$ and maximizes the criteria functions $f_{s}$ with:

$$
\begin{gathered}
f_{r}=\sum_{i=1}^{n} \sum_{q=1}^{z} c_{i r q} x_{i q}, \quad(r=1,2, \ldots, p) \\
f_{s}=\sum_{i=1}^{n} \sum_{q=1}^{z} c_{i s q} x_{i q}, \quad(s=p+1, p+2, \ldots, k)
\end{gathered}
$$

and constraints:

$$
\underline{x} \in X_{d}, \quad X_{d}=\left\{\begin{array}{l}
\underline{x} \mid g_{l}(\underline{x})=\sum_{i=1}^{n} a_{i l} x_{i q} \geq a_{q} b_{l q}, \sum_{i=1}^{n} x_{i q}=a_{q}, \sum_{q=1}^{z} x_{i q} \leq d_{i}, t_{i q} \leq x_{i q} \leq u_{i q}, \\
l=1,2, \ldots, m, i=1,2, \ldots, n, q=1, \ldots, z
\end{array}\right\}
$$

where $c_{i r q}, c_{i s q}, a_{i l}, b_{l q}, u_{i q}$ and $t_{i q}$ are crisp or fuzzy values.

Zimmermann (1978) solved the problem (equation (8)-equation (10)) by fuzzy linear programming. He formulated the fuzzy linear program by determining for each criteria function $f_{j}$ its maximal value $f_{j}^{+}$and its minimal value $f_{j}^{-}$, solving:

$$
\begin{aligned}
& f_{r}^{+}=\max f_{r}, \quad \underline{x} \in X_{a}, \quad f_{r}^{-}=\min f_{r}, \quad \underline{x} \in X_{d} \\
& f_{s}^{+}=\max f_{s}, \quad \underline{x} \in X_{d}, \quad f_{s}^{-}=\min f_{s}, \quad \underline{x} \in X_{a}
\end{aligned}
$$

$f_{r}^{-}, f_{s}^{+}$are obtained by solving multicriteria model as a linear programming model separately minimizing or maximizing particular criteria functions, $\underline{x} \in X_{d}$ means that solutions have to satisfy the constraints, while $X_{a}$ is a set of all optimal solutions obtained by solving particular criteria functions.

As for each criteria function $f_{j}$ its value is changed linearly from $f_{j}^{-}$to $f_{j}^{+}$, this value can be observed as a fuzzy number with the linear membership function $\mu_{f_{j}}(\underline{x})$. Consequently, the FMCP model (equation (8)-equation (10)) with fuzzy goals and fuzzy constraints can be presented as:

$$
\begin{aligned}
& \tilde{f_{r}}=\sum_{i=1}^{n} \sum_{q=1}^{z} c_{i r q} x_{i q} \leq \approx f_{r}^{0}, \quad(r=1,2, \ldots, p) \\
& \tilde{f_{s}}=\sum_{i=1}^{n} \sum_{q=1}^{z} c_{i s q} x_{i q} \geq \approx f_{s}^{0}, \quad(s=p+1, p+2, \ldots, k)
\end{aligned}
$$

subject to:

$$
g_{l}(\underline{x})=\sum_{i=1}^{n} a_{i l} x_{i q} \geq \approx a_{q} b_{l q}, \quad(l=1, \ldots, m, q=1, \ldots, z)
$$




$$
\begin{gathered}
\sum_{i=1}^{n} x_{i q}=a_{q}, \quad(q=1, \ldots, z) \\
\sum_{q=1}^{z} x_{i q} \leq d_{i}, \quad(i=1, \ldots, n) \\
t_{i q} \leq x_{i q} \leq u_{i q}, \quad(i=1, \ldots, n, q=1, \ldots, z)
\end{gathered}
$$

In this model, the sign " $\approx$ " indicates fuzzy environment. The symbol " $\leq \approx$ " indicates the fuzzy version of the sign " $\leq$ ", and is interpreted as "essentially smaller than or equal to" while the symbol " $\geq \approx$ " is interpreted as "essentially greater than or equal to". $f_{r}^{0}$ and $f_{s}^{0}$ represent aspiration levels of criteria functions that would be achieved by the decision maker.

If we assume that the membership functions, which are based on preference of satisfaction, are linear, then the linear membership functions for criteria functions and constraints can be presented as follows:

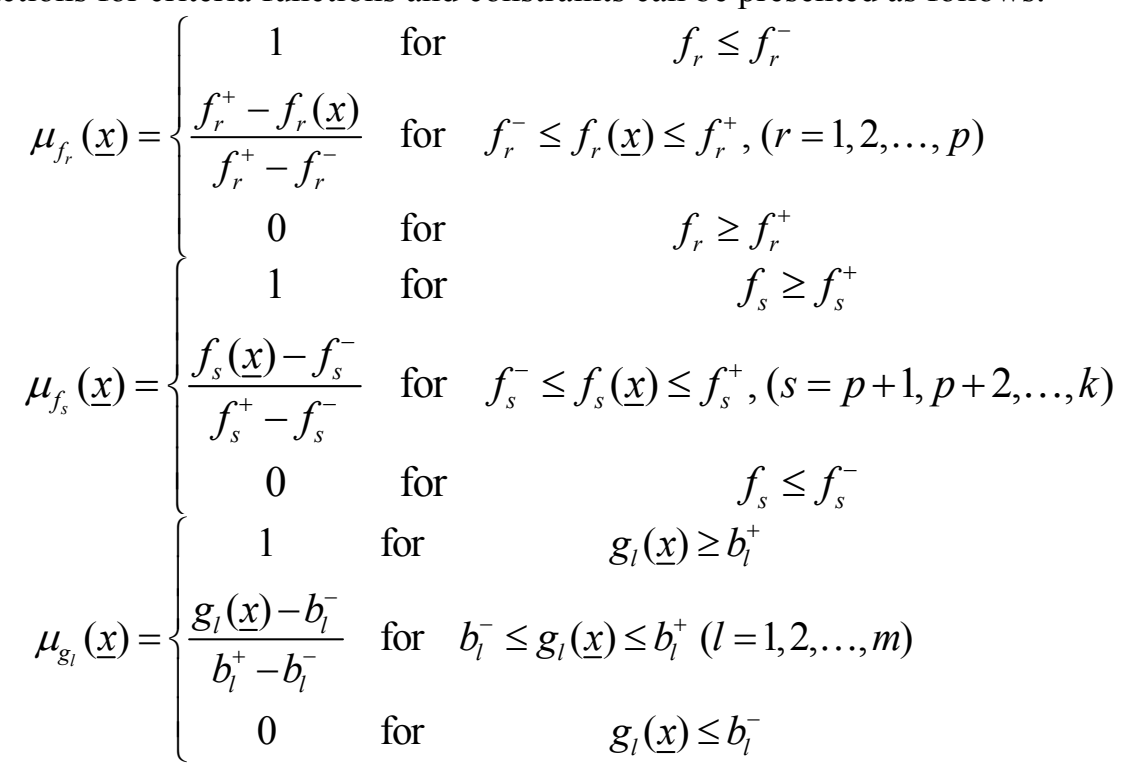

where $b_{l}^{-}=b_{l}$, and $b_{l}^{+}=b_{l}+d_{l} . d_{l}$ are subjectively determined constants that express the borders of allowed deviations of $k$ inequality (tolerance interval).

In the fuzzy programming model, according to Zimmermann's approach, the fuzzy solution represents an intersection of all the fuzzy sets that represent fuzzy criteria functions and fuzzy constraints. The fuzzy solution for all the fuzzy goals and fuzzy constraints is given as follows:

$$
\mu_{D}(\underline{x})=\left\{\left\{\bigcap_{j=1}^{k} \mu_{f_{j}}(\underline{x})\right\} \cap\left\{\bigcap_{l=1}^{m} \mu_{g_{l}}(\underline{x})\right\}\right\}
$$

The optimal solution $\left(\underline{x}^{*}\right)$ is:

$$
\mu_{D}\left(\underline{x}^{*}\right)=\max _{\underline{x} \in X_{D}} \mu_{D}(\underline{x})=\max _{\underline{x} \in X_{D}} \min \left[\min _{j=1, \ldots, k} \mu_{f_{j}}(\underline{x}), \min _{l=1, \ldots, m} \mu_{g_{l}}(\underline{x})\right]
$$

The optimal solution $\left(\underline{x}^{*}\right)$ of the above model is equivalent to the solving of the following linear programming model (Zimmermann, 1987):

$$
(\max ) \lambda
$$

subject to:

$$
\lambda \leq \mu_{f_{j}}(\underline{x}), \quad j=1,2, \ldots, k
$$




$$
\begin{aligned}
\lambda \leq \mu_{g_{l}}(\underline{x}), \quad(l=1, \ldots, m) \\
\sum_{i=1}^{n} x_{i q}=a_{q}, \quad(q=1, \ldots, z) \\
\sum_{q=1}^{z} x_{i q} \leq d_{i}, \quad(i=1, \ldots, n) \\
t_{i q} \leq x_{i q} \leq u_{i q}, \quad(i=1, \ldots, n, q=1, \ldots z) \\
\lambda \in[0,1]
\end{aligned}
$$

where $\mu_{D}(\underline{x})$ represents the membership function for the optimal solution, $\mu_{f_{j}}(\underline{x})$ represents the membership functions for criteria functions and $\mu_{g_{l}}(\underline{x})$ represents the membership functions for constraints. In this model, the relationship between constraints and criteria functions is completely symmetrical and here the decision maker cannot express the relative value of criteria functions and constraints (Zimmermann, 1987).

In order to express the relative importance of criteria functions and constraints, we have to solve the so called weight additive model in which weights present utility functions of criteria functions and constraints (Bellman \& Zadeh, 1970; Sakawa, 1993; Tiwari, Dharmahr \& Rao, 1987; Amid, Ghodsypour \& O’Brien, 2006).

This convex fuzzy model is:

$$
\begin{gathered}
\mu_{D}(\underline{x})=\sum_{j=1}^{k} w_{j} \mu_{f_{j}}(\underline{x})+\sum_{l=1}^{m} \beta_{l} \mu_{g_{l}}(\underline{x}) \\
\sum_{j=1}^{k} w_{j}+\sum_{l=1}^{m} \beta_{l}=1, \quad w_{j}, \beta_{l} \geq 0
\end{gathered}
$$

where $w_{j}$ and $\beta_{l}$ are weight coefficients representing the relative importance between the fuzzy criteria functions and fuzzy constraints.

To solve the above fuzzy model, we will use the following linear programming model:

subject to:

$$
(\max ) f=\sum_{j=1}^{k} w_{j} \lambda_{j}+\sum_{l=1}^{m} \beta_{l} \gamma_{l}
$$

$$
\begin{gathered}
\lambda_{j} \leq \mu_{f_{j}}(\underline{x}), \quad(j=1, \ldots, k) \\
\gamma_{l} \leq \mu_{g_{l}}(\underline{x}), \quad(l=1, \ldots, m) \\
\sum_{i=1}^{n} x_{i q}=a_{q}, \quad(q=1, \ldots, z) \\
\sum_{q=1}^{z} x_{i q} \leq d_{i}, \quad(i=1, \ldots, n) \\
t_{i q} \leq x_{i q} \leq u_{i q}, \quad(i=1, \ldots, n, q=1, \ldots z) \\
\lambda_{j}, \beta_{l} \in[0,1], \quad(j=1, \ldots, k ; l=1, \ldots, m) \\
\lambda_{j} \geq w_{j}, \quad(j=1, \ldots, k) \\
\gamma_{l} \geq \beta_{l}, \quad(l=1, \ldots, m)
\end{gathered}
$$

\subsection{Analysis of the obtained solutions}

The analysis of the obtained solutions should point to the robustness of the obtained results. After applying fuzzy linear programming, we have to test the sensitivity of the obtained results in terms of changes in criteria functions weights, which should help the decision maker in selection of the preferred solution. 


\section{Case study}

\subsection{Input data}

The authors will establish the FMCP model to optimize feed blend production in a company dealing with pig farming and preparation of feed blend, and then, the authors will solve the obtained model by application of linear programming, optimizing separately each chosen criteria function and eventually applying a fuzzy multi-criteria programming method to obtain a weakly Pareto optimal solution.

In agreement with the decision maker, the optimization criteria are defined: (1) total blends cost minimization, (2) maximization of the total digestibility of feeds in the blends, and (3) minimization of total water in the blends. It is to be noted that this work focuses on the methodology of problem solving, and that the choice of criteria is arbitrary, which may not be approved by some readers.

The subsequent breakdown gives the data necessary for optimization of production of 5 different sorts of feed blend for pigs: PS-1 pigs weighing up to $15 \mathrm{~kg}$, PS-2 pigs weighing 15-25 kg, PS-3 pigs weighing 25-60 kg, PS-4 pigs weighing 60-100 kg, and PS-5 pigs weighing over $100 \mathrm{~kg}$. For the coming period of one month the required quantities are: $10,000 \mathrm{~kg}$ of blend PS-1 $\left(a_{1}\right), 20,000 \mathrm{~kg}$ of blend PS-2 $\left(a_{2}\right), 30,000 \mathrm{~kg}$ of blend PS-3 $\left(a_{3}\right), 50,000 \mathrm{~kg}$ of blend PS-4 $\left(a_{4}\right)$ and $20,000 \mathrm{~kg}$ of blend PS-5 $\left(a_{5}\right)$. The optimal production is to meet the requirements for minimal and maximal quantities of nutrients in the blends. Besides, it is necessary to meet the requirement for the necessary quantities of the feed blends for this period considering the constraint in terms of ingredients availability. Determination of minimal and maximal shares of nutrients in the feed blend is based on scientific research. It has to be noted that due to the varying quality of ingredients prior to the preparation of feed blends, it is necessary to analyze the content of nutrients in all the available ingredients. All the data are shown in Table 1, Table 2 and Table 3.

The ingredients for pig feed blends, their purchasing price per unit, the percentage of the digestibility of feeds and water per ingredient unit as well as the available quantity are shown in Table 1.

Table 1 Sorts of feed

\begin{tabular}{|c|c|c|c|c|c|}
\hline \multicolumn{2}{|c|}{ Sorts of feed } & \multirow{2}{*}{$\frac{\text { Price: } c_{i 1}(\mathrm{~min})}{1.75}$} & \multirow{2}{*}{$\begin{array}{l}\text { Digestibility: } c_{i 2}(\max ) \\
70\end{array}$} & \multirow{2}{*}{$\begin{array}{l}\text { Water: } c_{i 3}(\mathrm{~min}) \\
11\end{array}$} & \multirow{2}{*}{$\begin{array}{l}\text { Available quantity in kg: } d_{i} \\
30,000\end{array}$} \\
\hline $\mathrm{H} 1$ & Barley & & & & \\
\hline $\mathrm{H} 2$ & Maize & 1.75 & 80 & 12 & 50,000 \\
\hline H3 & Lucerne & 1.65 & 32 & 6.9 & 20,000 \\
\hline $\mathrm{H} 4$ & Powdered milk & 6 & 86 & 8.4 & 10,000 \\
\hline H5 & Fish meal & 9 & 69 & 9 & 20,000 \\
\hline H6 & Soya & 2.7 & 92 & 10 & 2,000 \\
\hline H7 & Soya hulls & 3.5 & 79 & 11 & 2,000 \\
\hline H8 & Dried whey & 9 & 78 & 6 & 5,000 \\
\hline H9 & Rape pellets & 1.8 & 66 & 8.0 & 20,000 \\
\hline $\mathrm{H} 10$ & Wheat & 1.8 & 79 & 12 & 70,000 \\
\hline H11 & Rye & 1.8 & 75 & 11.4 & 40,000 \\
\hline H12 & Millet & 3.5 & 65 & 10.0 & 40,000 \\
\hline H13 & Sunflower pellets & 1.8 & 68 & 7.0 & 20,000 \\
\hline
\end{tabular}


Table 2 Needs for nutrients

\begin{tabular}{llllllll}
\hline Nutrients & $\begin{array}{l}\text { Constraint } \\
\text { type }\end{array}$ & $\begin{array}{l}\text { Min or } \\
\text { max req. } \\
\text { PS-1 }\left(b_{k 1}\right)\end{array}$ & $\begin{array}{l}\text { Min or } \\
\text { max req. } \\
\text { PS-2 }\left(b_{k 2}\right)\end{array}$ & $\begin{array}{l}\text { Min or } \\
\text { max req. } \\
\text { PS-3 }\left(b_{k 3}\right)\end{array}$ & $\begin{array}{l}\text { Min or } \\
\text { maxreq. } \\
\text { PS-4 }\left(b_{\mathrm{k} 4}\right)\end{array}$ & $\begin{array}{l}\text { Min or } \\
\text { max req. } \\
\text { PS-5 }\left(b_{k 5}\right)\end{array}$ \\
\hline E1 & Raw protein (\%) & $\geq$ & 20 & 18 & 16 & 14 & 13 \\
E2 & Pulp (\%) & $\leq$ & 4 & 6 & 7 & 7 & 9 \\
E3 & Calcium-Ca (\%) & $\leq$ & 1.2 & 1.1 & 0.9 & 0.8 & 1 \\
E4 & Phosporus-P(\%) & $\geq$ & 0.6 & 0.5 & 0.5 & 0.5 & 0.50 \\
E5 & Ash (\%) & $\leq$ & 8 & 8 & 8 & 8 & 8 \\
E6 & Metionin (\%) & $\geq$ & 0.70 & 0.55 & 0.45 & 0.40 & 0.25 \\
E7 & Lizin (\%) & $\geq$ & 1.30 & 1.00 & 0.70 & 0.60 & 0.50 \\
E8 & Triptofan (\%) & $\geq$ & 0.18 & 0.15 & 0.11 & 0.11 & 0.11 \\
E9 & Treonin (\%) & $\geq$ & 0.69 & 0.56 & 0.44 & 0.41 & 0.40 \\
E10 & Izoleucin (\%) & $\geq$ & 0.69 & 0.56 & 0.44 & 0.41 & 0.41 \\
E11 & Histidin (\%) & $\geq$ & 0.25 & 0.20 & 0.16 & 0.15 & 0.15 \\
E12 & Valin (\%) & $\geq$ & 0.69 & 0.56 & 0.44 & 0.41 & 0.41 \\
E13 & Leucin (\%) & $\geq$ & 0.83 & 0.68 & 0.52 & 0.48 & 0.48 \\
E14 & Arginin (\%) & $\geq$ & 0.28 & 0.23 & 0.18 & 0.16 & 0.16 \\
E15 & Fenkalanin (\%) & $\geq$ & 0.69 & 0.56 & 0.44 & 0.41 & 0.41 \\
E16 & Copper (mg) & $\geq$ & 6 & 6 & 0 & 0 & 20 \\
E17 & Iodine (mg) & $\geq$ & 0.20 & 0.20 & 0.20 & 0.20 & 0.20 \\
E18 & Iron (mg) & $\geq$ & 80 & 80 & 0 & 0 & 80 \\
E19 & Mangan (mg) & $\geq$ & 20 & 20 & 20 & 20 & 30 \\
E20 & Sedan (mg) & $\geq$ & 0.10 & 0.10 & 0.10 & 0.10 & 0.10 \\
\hline
\end{tabular}

Table 3 Nutrition matrix $\left(a_{i l}\right)$

\begin{tabular}{lccccccccccccc}
\hline & H1 & H2 & H3 & H4 & H5 & H6 & H7 & H8 & H9 & H10 & H11 & H12 & H13 \\
\hline E1 & 11.5 & 8.9 & 17.0 & 33 & 61 & 38 & 42 & 12 & 36 & 13.5 & 12.6 & 11.0 & 42 \\
E2 & 5.0 & 2.9 & 24.0 & 0.0 & 1.0 & 5.0 & 6.5 & 0.0 & 13.2 & 3.0 & 2.8 & 10.5 & 13.0 \\
E3 & 0.08 & 0.01 & 1.3 & 1.25 & 7.0 & 0.25 & 0.2 & 0.87 & 0.6 & 0.05 & 0.08 & 0.1 & 0.4 \\
E4 & 0.42 & 0.25 & 0.23 & 1.0 & 3.5 & 0.59 & 0.6 & 0.79 & 0.93 & 0.41 & 0.3 & 0.35 & 1.0 \\
E5 & 2.5 & 1.5 & 9.6 & 8.0 & 24 & 4.6 & 6.0 & 9.7 & 7.2 & 2.0 & 1.45 & 4.0 & 7.7 \\
E6 & 0.18 & 0.17 & 0.28 & 0.98 & 1.65 & 0.54 & 0.6 & 0.2 & 0.67 & 0.25 & 0.16 & 0.2 & 1.5 \\
E7 & 0.53 & 0.22 & 0.73 & 2.6 & 4.3 & 2.4 & 2.7 & 1.1 & 2.12 & 0.4 & 0.4 & 0.4 & 1.7 \\
E8 & 0.17 & 0.09 & 0.45 & 0.45 & 0.7 & 0.52 & 0.65 & 0.2 & 0.46 & 0.18 & 0.14 & 0.18 & 0.5 \\
E9 & 0.36 & 0.34 & 0.75 & 1.75 & 2.6 & 1.69 & 1.7 & 0.8 & 1.6 & 0.35 & 0.36 & 0.28 & 1.5 \\
E10 & 0.42 & 0.37 & 0.84 & 2.1 & 3.1 & 2.18 & 2.8 & 0.9 & 1.41 & 0.69 & 0.53 & 0.53 & 2.1 \\
E11 & 0.23 & 0.19 & 0.35 & 0.86 & 1.93 & 1.01 & 1.1 & 0.2 & 0.95 & 0.17 & 0.27 & 0.18 & 1.0 \\
E12 & 0.62 & 0.42 & 1.04 & 2.38 & 3.25 & 2.02 & 2.2 & 0.7 & 1.81 & 0.69 & 0.62 & 0.62 & 2.3 \\
E13 & 0.8 & 1.0 & 1.3 & 3.3 & 4.5 & 2.8 & 3.8 & 1.2 & 2.6 & 1.0 & 0.7 & 0.9 & 2.6 \\
E14 & 0.5 & 0.52 & 0.75 & 1.1 & 4.2 & 2.8 & 3.2 & 0.4 & 2.04 & 0.6 & 0.5 & 0.8 & 3.5 \\
E15 & 0.62 & 0.44 & 0.91 & 1.58 & 2.8 & 2.1 & 2.1 & 0.4 & 1.41 & 0.78 & 0.62 & 0.62 & 2.2 \\
E16 & 6 & 3.2 & 0 & 11.7 & 8 & 17 & 0 & 4 & 6 & 6 & 15 & 10 & 0 \\
E17 & 0.05 & 0 & 0 & 0.9 & 5.2 & 0 & 0 & 0 & 0.6 & 0.04 & 0.05 & 0.02 & 0 \\
E18 & 80 & 20 & 0 & 3 & 635 & 90 & 0 & 0 & 160 & 50 & 65 & 40 & 0 \\
E19 & 25 & 4.9 & 0 & 2 & 73 & 35 & 0 & 4.2 & 53 & 30 & 80 & 10 & 23 \\
E20 & 0.15 & 0.04 & 0 & 0.12 & 4.3 & 0 & 0 & 0 & 1 & 0.06 & 0.10 & 0.07 & 0 \\
\hline & & & & & & & & & & & &
\end{tabular}

The nutrients that have to be contained in the feed blend (in compliance with the requirements of nutritionists) are shown in Table 2. In addition to that, the table shows the nutritionists' requirements, for particular nutrients in 
the special blends prepared for five different categories of pigs. Some of the nutrients are given in terms of minimal and some in terms of maximal requirements.

The data in Table 3 are applied in optimization of feed blend production and are the same for each sort of feed blend.

Table 3 is a nutrition matrix and its elements $a_{i l}$ are the contents of particular nutrient in the feed unit.

The model also includes additional constraints on the quantity of particular sorts of feed. Namely, to make the diet plan as heterogeneous as possible, the model limits the share of any ingredient to maximally $15 \%$. Thus, if $x_{i q}$ is the share of $i$ feed in the $q$ optimal blend, the constraints $x_{i q} \leq 0.15,(i=1, \ldots, 13 ; q=1, \ldots, 5)$ are introduced.

\subsection{Model for optimization of feed blend production}

Considering the data given in the above tables and the requirements of the decision maker, a multi-criteria linear programming model is formed in which the function of total production costs is minimized as well as the function of the total share of water in the feed blends, while the function of the total digestibility of the feeds in the blends is maximized. Thus, the following multi-criteria linear programming (MCLP) model is formed.

Function of total costs:

$$
(\min ) f_{1}=\sum_{i=1}^{13} \sum_{q=1}^{5} c_{i 1 q} x_{i q}
$$

Function of total digestibility of feeds:

$$
(\max ) f_{2}=\sum_{i=1}^{13} \sum_{q=1}^{5} c_{i 2 q} x_{i q}
$$

Function of total share of water:

$$
\text { (min) } f_{3}=\sum_{i=1}^{13} \sum_{q=1}^{5} c_{i 3 q} x_{i q}
$$

subject to:

Technological constraints:

$$
\sum_{i=1}^{13} a_{i l q} x_{i q} \geq a_{q} b_{l q}(l=1, \ldots, 20 ; q=1, \ldots, 5)
$$

Ingredients availability constraint:

$$
\sum_{q=1}^{5} x_{i q} \leq d_{i} \quad(i=1, \ldots, 13)
$$

Necessary quantities of feed blends:

$$
\sum_{i=1}^{13} x_{i q}=a_{q} \quad(q=1, \ldots, 5)
$$

Non-negativity and upper bound constraints:

$$
0 \leq x_{i q} \leq 0.15 a_{q}(i=1, \ldots, 13 ; q=1, \ldots, 5)
$$

This means that the model has 65 variables and 118 constraints, and it is first solved by optimization of each of the three criteria functions on the given set of constraints. In this way, we obtain marginal solutions and the payoff table. The obtained marginal solutions are shown in Table 4. 
Table 4 Payoff table

\begin{tabular}{llll}
\hline & $f_{1}: \min$ & $f_{2}: \max$ & $f_{3}: \min$ \\
\hline$x_{1}^{*}$ & 276,021 & $9,364,810$ & $1,314,031$ \\
& $\left(100.00 \%\right.$ of $\left.f_{1}^{*}\right)$ & $\left(95.81\right.$ of $\left.f_{2}^{*}\right)$ & $\left(108.28 \%\right.$ of $\left.f_{3}^{*}\right)$ \\
$x_{2}^{*}$ & $408,491.4$ & $9,774,339$ & $1,317,120$ \\
& $\left(147.99 \%\right.$ of $\left.f_{1}^{*}\right)$ & $\left(100.00 \%\right.$ of $\left.f_{2}^{*}\right)$ & $\left(108.53 \%\right.$ of $\left.f_{3}^{*}\right)$ \\
$x_{3}^{*}$ & $422,990.2$ & $9,265,424$ & $1,213,584$ \\
& $\left(153.25 \%\right.$ of $\left.f_{1}^{*}\right)$ & $\left(94.79 \%\right.$ of $\left.f_{2}^{*}\right)$ & $\left(100.00 \%\right.$ of $\left.f_{3}^{*}\right)$ \\
\hline
\end{tabular}

The conflict of criteria functions is evident from the payoff table: optimization of the model by one of the given criteria functions results in an inadequate value of the other two criteria functions. This points to the fact that the model is a multicriteria model and that it is necessary to find a compromise non-dominated solution according to the decision maker's preferences.

In order to obtain the so called best compromise solution, the problem has to be solved by one of the multicriteria programming methods. In agreement with the decision maker (farm owner), it was decided to solve the problem by reformulating it into a corresponding fuzzy programming model, where the values of criteria functions are taken as fuzzy, while the constraints are taken as crisp values. To form the fuzzy MCP model, we use the data from the payoff table (see Table 4), where $f_{1}^{-}=f_{1}^{*}=276021 ; \quad f_{1}^{+}=f_{1}^{\max }=422990.2 ; \quad f_{2}^{+}=f_{2}^{*}=9774339$; $f_{2}^{-}=f_{2}^{\min }=9265424 ; \quad f_{3}^{-}=f_{3}^{*}=1213584 ; \quad f_{3}^{+}=f_{3}^{\max }=1317120$. Using the above data, and according to the relations (equation (19)-equation (21)), we form the membership functions for criteria functions:

$$
\begin{aligned}
& \mu_{f_{1}}(\underline{x})=\left\{\begin{array}{ccc}
1 & \text { for } & f_{1}(\underline{x}) \leq 276021 \\
\frac{422990.2-f_{1}(\underline{x})}{422990.2-276021} & \text { for } & 276021 \leq f_{1}(\underline{x}) \leq 422990.2 \\
0 & \text { for } & f_{1}(\underline{x}) \geq 422990.2
\end{array}\right. \\
& \mu_{f_{2}}(\underline{x})=\left\{\begin{array}{ccc}
1 & \text { for } & f_{2}(\underline{x}) \geq 9774339 \\
\frac{f_{2}(\underline{x})-9265424}{9774339-9265424} & \text { for } & 9265424 \leq f_{2}(\underline{x}) \leq 9774339 \\
0 & \text { for } & f_{2}(\underline{x}) \leq 9265424 \\
1 & \text { for } & f_{3}(\underline{x}) \leq 1213584
\end{array}\right. \\
& \mu_{f_{3}}(\underline{x})=\left\{\begin{array}{ccc}
\frac{1317120-f_{3}(\underline{x})}{1317120-1213584} & \text { for } & 1213584 \leq f_{3}(\underline{x}) \leq 1317120 \\
0 & \text { for } & f_{3}(\underline{x}) \geq 1317120
\end{array}\right.
\end{aligned}
$$

Based on the formed membership functions and considering the information on the relative importance of criteria functions and constraints obtained from the decision maker $\left(w_{1}=0.4, w_{2}=0.35, \quad w_{3}=0.25\right)$, we from the additive model of fuzzy MCP:

subject to:

$$
(\max ) f=0.40 \lambda_{1}+0.35 \lambda_{2}+0.25 \lambda_{3}
$$

$$
\begin{gathered}
\lambda_{1} \leq \mu_{f_{1}}(\underline{x}), \quad \lambda_{2} \leq \mu_{f_{2}}(\underline{x}), \quad \lambda_{3} \leq \mu_{f_{3}}(\underline{x}) \\
\sum_{i=1}^{13} a_{i l} x_{i q} \geq a_{q} b_{l q} \quad(l=1, \ldots, 20 ; q=1, \ldots, 5) \\
\sum_{q=1}^{5} x_{i q} \leq d_{i}, \quad(i=1, \ldots, 13)
\end{gathered}
$$




$$
\begin{aligned}
& \sum_{i=1}^{13} x_{i q}=a_{q} \quad(q=1, \ldots, 5) \\
0 & \leq x_{i q} \leq 0.15 a_{q} \quad(i=1, \ldots, 13 ; q=1, \ldots, 5) \\
0.4 & \leq \lambda_{1} \leq 1, \quad 0.35 \leq \lambda_{2} \leq 1, \quad 0.25 \leq \lambda_{3} \leq 1
\end{aligned}
$$

The model (equation (52)-equation (58)) is an LP model whose compromise solution is shown in Table 5 and Table 6.

From Table 5, it is obvious that the function $f_{1}$ has coefficient $\lambda_{1}=0.686059$, the function $f_{2}$ coefficient $\lambda_{2}=0.8567913$, and the function $f_{3}$ coefficient $\lambda_{3}=0.2500$. This is the consequence of the chosen values of weight coefficients: $w_{1}=0.4, w_{2}=0.35, w_{3}=0.25$. In order to show that the values $\lambda_{1}, \lambda_{2}, \lambda_{3}$ and $f_{1}, f_{2}$, $f_{3}$ reflect the values of weight coefficients determined by the decision maker, the authors solve several models with different values of weight coefficients. Some compromise solutions are shown in Table 7, and Fig. 1 illustrates the indicators from Table 7.

From Table 7, we can see that the increase of weight $w_{1}$ from 0.10 to 0.40 with simultaneous reduction of the weight $w_{2}$, and keeping the weight $w_{3}$ constant, does not result in changes of criteria functions values. However, the increase of the weight $w_{1}$ above 0.40 leads to more significant changes in criteria functions values. It is to be noted that the changes in criteria functions weights are directly reflected in their values obtained by application of the proposed methodology. The analysis of the obtained solutions reveals that they reflect the preferences of the decision maker expressed by values of criteria functions weights.

Table 5 Compromise solution

\begin{tabular}{lccccc}
\hline & $x_{i 1}$ & $x_{i 2}$ & $x_{i 3}$ & $x_{i 4}$ & $x_{i 5}$ \\
\hline Barley & 0 & 914.5819 & 4,500 & 7,500 & $1,253.6830$ \\
Maize & 1,500 & 3,000 & 4,500 & 7,500 & 3,000 \\
Lucerne & 0 & 0 & 0 & 0 & 0 \\
Powdered milk & 1,500 & 43.6025 & $1,767.204$ & $4,614.3980$ & $2,074.7950$ \\
Fish meal & $1,091.0500$ & 727.0908 & 207.5993 & 57.1234 & 0 \\
Soya & 0 & 2,000 & 0 & 0 & 0 \\
Soya hulls & 0 & 0 & 0 & 328.4784 & $1,671.522$ \\
Dried whey & 1,500 & $1,314.7250$ & $1,025.197$ & 0 & 0 \\
Rape pellets & 635.9510 & 3,000 & 4,500 & 7,500 & 3,000 \\
Wheat & 1,500 & 3,000 & 4,500 & 7,500 & 3,000 \\
Rye & 772.9987 & 3,000 & 4,500 & 7,500 & 3,000 \\
Millet & 0 & 0 & 0 & 0 & 0 \\
Sunflower pellets & 1,500 & 3,000 & 4,500 & 7,500 & 3,000 \\
\hline
\end{tabular}

Table 6 Compromise solution: functions value

\begin{tabular}{llll}
\hline & $f_{1}: \min$ & $f_{2}: \max$ & $f_{3}: \min$ \\
\hline$x^{\text {com } 1}$ & $322,160.6\left(116.72 \%\right.$ of $\left.f_{1}^{*}\right)$ & $9,701,458\left(99.25 \%\right.$ of $\left.f_{2}^{*}\right)$ & $1,291,236\left(106.40 \%\right.$ of $\left.f_{3}^{*}\right)$ \\
\hline
\end{tabular}

Here, the authors shall briefly analyse the first compromise solution obtained by solving the model (equation (52)-equation (58)). The analysis of this compromise solution shows that:

(1) The compromise solution contains eleven ingredients except lucerne and millet;

(2) To produce the blend PS-1 and PS-5, it is necessary to use eight different ingredients, for PS-2 ten, while for blends PS-3 and PS-4 nine ingredients are needed; 
(3) To produce the given feed blend quantity, the available ingredients $x_{4}, x_{6}, x_{7}$ are used up completely, while the ingredient $x_{1}$ is used by $47.23 \%$, the ingredient $x_{2}: 39 \%, x_{5}: 10.41 \%, x_{8}: 76.80 \%, x_{9}: 93.18 \%, x_{10}: 27.86$ $\%, x_{11}: 46.93 \%$, and $x_{13}$ is used by $97.50 \%$;

(4) The number of the used ingredients is increased by introduction of additional constraints that limit the share of a particular ingredient in the blend.

Table 7 Compromise solutions: values for $w, \lambda, f_{1}, f_{2}$ and $f_{3}$

\begin{tabular}{|c|c|c|c|c|c|c|}
\hline \multirow{2}{*}{\multicolumn{3}{|c|}{ Solution $w$}} & \multirow{3}{*}{$\begin{array}{l}\lambda \\
\lambda_{1}=0.6242, \lambda_{2}=0.8832 \\
\lambda_{3}=0.3003\end{array}$} & \multicolumn{3}{|c|}{ Values of criteria functions } \\
\hline & & & & \multirow{2}{*}{$\begin{array}{l}f_{1} \\
331,246.8 \\
\left(116.38 \% \text { of } f_{1}^{*}\right)\end{array}$} & \multirow{2}{*}{$\begin{array}{l}f_{2} \\
9,714,923 \\
\left(99.39 \% \text { of } f_{2}^{*}\right)\end{array}$} & \multirow{2}{*}{$\begin{array}{l}f_{3} \\
1,286,027 \\
\left(105.97 \% \text { of } f_{3}^{*}\right)\end{array}$} \\
\hline$\underline{x}_{1}^{\text {com }}$ & $\begin{array}{l}w_{1}=0.10 \\
w_{3}=0.25\end{array}$ & $w_{2}=0.65$ & & & & \\
\hline$\underline{x}_{2}^{\text {com }}$ & $\begin{array}{l}w_{1}=0.20 \\
w_{3}=0.25\end{array}$ & $w_{2}=0.55$ & $\begin{array}{l}\lambda_{1}=0.6242, \lambda_{2}=0.8832 \\
\lambda_{3}=0.3003\end{array}$ & $\begin{array}{l}331,246.8 \\
\left(116.38 \% \text { of } f_{1}^{*}\right)\end{array}$ & $\begin{array}{l}9,714,923 \\
\left(99.39 \% \text { of } f_{2}^{*}\right)\end{array}$ & $\begin{array}{l}1,286,027 \\
\left(105.97 \% \text { of } f_{3}^{*}\right)\end{array}$ \\
\hline$\underline{x}_{3}^{\text {com }}$ & $\begin{array}{l}w_{1}=0.30 \\
w_{3}=0.25\end{array}$ & $w_{2}=0.45$ & $\begin{array}{l}\lambda_{1}=0.6242, \lambda_{2}=0.8832 \\
\lambda_{3}=0.3003\end{array}$ & $\begin{array}{l}331,246.8 \\
\left(116.38 \% \text { of } f_{1}^{*}\right)\end{array}$ & $\begin{array}{l}9,714,923 \\
\left(99.39 \% \text { of } f_{2}^{*}\right)\end{array}$ & $\begin{array}{l}1,286,027 \\
\left(105.97 \% \text { of } f_{3}^{*}\right)\end{array}$ \\
\hline$\underline{x}_{4}^{\text {com }}$ & $\begin{array}{l}w_{1}=0.50 \\
w_{3}=0.25\end{array}$ & $w_{2}=0.25$ & $\begin{array}{l}\lambda_{1}=0.7097, \lambda_{2}=0.8214 \\
\lambda_{3}=0.2500\end{array}$ & $\begin{array}{l}318,675.8 \\
\left(115.45 \% \text { of } f_{1}^{*}\right)\end{array}$ & $\begin{array}{l}9,683,300 \\
\left(99.07 \% \text { of } f_{2}^{*}\right)\end{array}$ & $\begin{array}{l}1,291,223 \\
\left(106.40 \% \text { of } f_{3}^{*}\right)\end{array}$ \\
\hline$\underline{x}_{5}^{c o m}$ & $\begin{array}{l}w_{1}=0.60 \\
w_{3}=0.25\end{array}$ & $w_{2}=0.15$ & $\begin{array}{l}\lambda_{1}=0.9439, \lambda_{2}=0.2087 \\
\lambda_{3}=0.2500\end{array}$ & $\begin{array}{l}284,266.2 \\
\left(102.99 \% \text { of } f_{1}^{*}\right)\end{array}$ & $\begin{array}{l}9,371,620 \\
\left(95.88 \% \text { of } f_{2}^{*}\right)\end{array}$ & $\begin{array}{l}1,291,236 \\
\left(106.40 \% \text { of } f_{3}^{*}\right)\end{array}$ \\
\hline
\end{tabular}

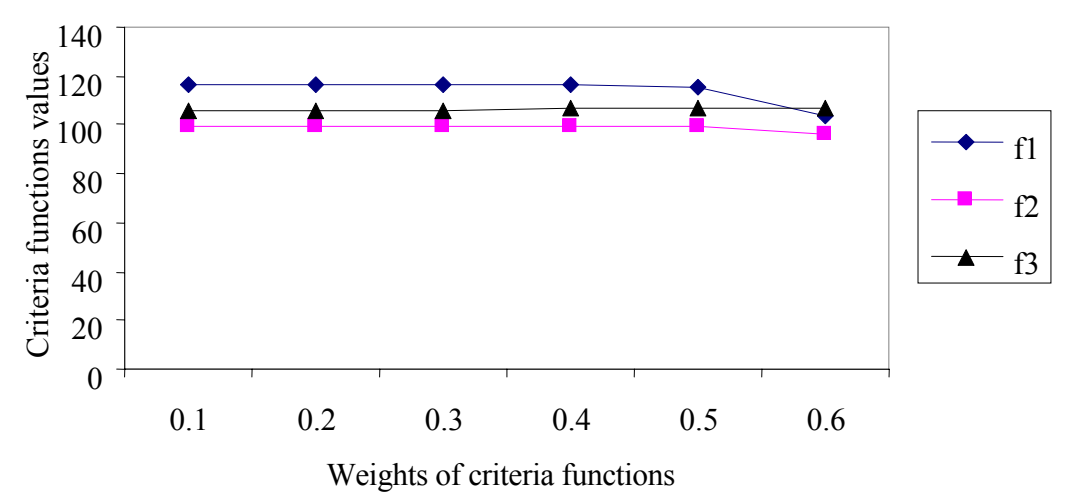

Fig. 1 Criteria functions values

Consequently, the analysis of marginal solutions and the obtained compromise solution shows the complexity of the feed blend optimization problem in case when there are constraints in available ingredients. From the obtained compromise solution, an optimal recipe can be calculated for each of the five blends. This is done dividing the obtained values $x_{i q}$ by the given blend quantity to be produced $a_{q}$.

The authors here have presented the possibility of application of only one fuzzy multicriteria programming method. The research is to be continued to test the applicability of other fuzzy multicriteria programming methods according to the adopted criteria. It is also necessary to investigate the possibility of incorporating the proposed model and methods into decision making support systems.

\section{Conclusions}

Based on the above we can make some general conclusions: 
(1) Production of feed blends is essentially a complex multicriteria problem.

(2) To solve the problem of feed blend optimization, an appropriate MLP model is to be formed and one of the MLP methods is to be applied to solve the obtained model.

(3) As the contribution of particular criteria functions to the achievement of the general company performance is fuzzy, the application of MLP methods requiring an active participation of the decision maker is limited.

(4) The solution to the stated problem may be achieved by the application of a fuzzy multicriteria programming method.

(5) The proposed methodology requires the decision maker to determine the weights of criteria functions and constraints, and it is not necessary to determine weights for all the criteria functions and constraint functions.

(6) This methodology allows a weak non-dominated solution with criteria functions and constraint values that reflect the preferences of the decision maker (Wierzbicki, 1986).

\section{References:}

Amid, A., Ghodsypour, S. H. \& O'Brien, C.. (2006). Fuzzy multiobjective linear model for supplier selection in supply chain. International Journal of Production Economics, 104, 394-407.

Bailleul, P. J., Rivest, J., Dubeau, F. \& Pomar, C.. (2001). Reducing nitrogen excretion in pigs by modifying the traditional least-cost formulation algorithm. Livestock Science, 72(3), 199-211.

Bellman, R. G. \& Zadeh, L. A.. (1970). Decision making in fuzzy environment. Management Sciences, 17, B141-B164.

Castrodeza, C., Lara, P. \& Pena, T.. (2005). Multicriteria fractional model for feed formulation: Economic, nutritional and environmental criteria. Agricultural Systems, 86, 79-96.

Lara, P.. (1993). Multiple objective fractional programming and livestock ration formulation: A case study for dairy cow diets in Spain. Agricultural Systems, 41, 321-334.

Lara, P. \& Romero, C.. (1992). An interactive multigoal programming model for determining livestock rations: An application to dairy cows in Andalusia, Spain. Journal of Operational Research Society, 43(3), 945-953.

Lara, P. \& Romero, C.. (1994). Relaxation of nutrient requirements on livestock rations through interactive multigoal programming. Agricultural Systems, 45, 443-453.

Mitani, K. \& Nakayama, H. A.. (1997). Multiobjective diet planning support system using the satisficing trade-off method. Journal of Multi-Criteria Decision Analysis, 6, 131-139.

National Research Council (NCR). (1998). Nutrient requirements of swine (10th ed.). Washington, DC: National Academy Press, 1998.

Perić, T.. (2008). Multi-criteria programming—Methods and applications (in Croatian). Zagreb: Alka script.

Perić, T. \& Babić, Z.. (2009). Determining optimal production program with a fuzzy multiple criteria programming method. In: Proceedings of International MultiConference of Engineers and Computer Scientists 2009, Hong Kong, 2006-2013.

Rehman, T. \& Romero, C.. (1984). Multiple-criteria decision-making techniques and their role in livestock ration formulation. Agricultural Systems, 15(1), 23-49.

Sakawa, M.. (1993). Fuzzy sets and interactive multiobjective optimization. New York: Plenum Press.

Tiwari, R. N., Dharmahr, S. \& Rao, J. R.. (1987). Fuzzy goal programming - An additive model. Fuzzy Sets and Systems, 24, $27-34$.

Tozer, P. R. \& Stokes, J. R.. (2001). A multi-objective programming approach to feed ration balancing and nutrient management. Agricultural Systems, 67, 201-215.

Wierzbicki, A. P.. (1986). On the completeness and constructiveness of parametric characterizations to vector optimization problems. OR Spectrum, 8(2), 73-87.

Zhang, F. \& Roush, W. B.. (2002). Multiple-objective (goal) programming model for feed formulation: An example for reducing nutrient variation. Poultry Science, 81, 182-192.

Zimmermann, H. J.. (1978). Fuzzy programming and linear programming with several objective functions. Fuzzy Sets and System, 1, 45-55.

Zimmermann, H. J.. (1987). Fuzzy sets, decision making and expert systems. Boston: Kluwer Academic Publishers.

Zimmermann, H. J.. (1993). Fuzzy sets theory and its applications. Boston: Kluwer Academic Publishers.

(Edited by Ruby and Chris) 